\title{
Cinética de Crescimento de Microrganismos Fermentativos Durante A Fermentação de Tucupi
}

\author{
Wellington Melo (I), Alessandra Santos Lopes (I), Vanessa Albres \\ Botelho (I), Gilson Chagas Junior (I)
}

(I) UFPA - Universidade Federal do Pará (Cidade Universitária José da Silveira Neto, campus Guamá.)

\section{Resumo}

Introdução: Existe uma grande variedade de produtos fermentados à base de mandioca, consumidos principalmente em países em desenvolvimento, que apresentam notáveis similaridades. Um desses produtos é o tucupi, um líquido levemente fermentado, de coloração amarelada que é obtido a partir do líquido extraído na prensagem de massa ralada de mandioca, principalmente de variedades com coloração amarela. Objetivos: Estudar o comportamento dos principais grupos de microrganismos envolvidos na fermentação da manipueira em Tucupi, assim como estudar a cinética das alterações químicas durante o processo. Material e Métodos: Cerca de 100 $\mathrm{kg}$ de mandioca da variedade Ouro Preto foram adquiridas no mercado do Ver-o-Peso, na cidade de Belém do Pará, onde foram descascadas e trituradas ainda no local de compra. A massa de mandioca triturada foi armazenada em sacos plásticos e transportada ao Laboratório de Fontes Amiláceas e Produtos Açucarados (LAFAMI) da Universidade Federal do Pará (UFPA). A massa foi para separação do resíduo líquido (manipueira). $O$ processo de fermentação natural ocorreu em três estufas com controle de temperatura a 20,30 e $40^{\circ} \mathrm{C}$. Como parâmetros de avaliação da fermentação foram medidos: $\mathrm{pH}$, teor de sólidos solúveis, acidez total titulável (ATT), contagem de bactérias aeróbias mesófilas e bolores e leveduras. Todas as análises foram realizadas em intervalos de 2 horas durante 16 horas de processo. A análise estatística dos resultados foi verificada pelos testes de Análise de Variância (ANOVA) a 5\% de

\footnotetext{
Referência:

Wellington Melo, Alessandra Santos Lopes, Vanessa Albres Botelho, Gilson Chagas Junior.Cinética de Crescimento de Microrganismos Fermentativos Durante A Fermentação de Tucupi. In: Anais do 12ㅇ Congresso Latinoamericano de Microbiologia e Higiene de Alimentos - MICROAL 2014 [= Blucher Food Science Proceedings, num.1, vol.1]. São Paulo: Editora Blucher, 2014. 
significância segundo o teste $F$, teste de Tukey $(p \leq 0,05)$, Correlação de Pearson e Análise de Regressão, com auxílio do software Statistica ${ }^{\circledR}$ 7.0. Resultados e Discussão: As contagens máximas de microrganismos aeróbios mesófilos nas temperaturas de 20,30 e $40{ }^{\circ} \mathrm{C}$ foram atingidos a 12 horas $(4,0 \times 107 \mathrm{UFC} / \mathrm{mL}), 8$ horas $\left(5,9 \times 10^{1} 0 \mathrm{UFC} / \mathrm{mL}\right)$ e 6 horas $\left(6,5 \times 10^{1} 0\right.$ $\mathrm{UFC} / \mathrm{mL}$ ) de fermentação, respectivamente. Os valores de acidez total dos tucupis fermentados nas temperaturas de 30 e $40^{\circ} \mathrm{C}$ por 8 e 6 horas respectivamente não apresentaram diferença estatística significativa ( $>0,05)$. O crescimento de bolores e leveduras foi maior na temperatura de $30^{\circ} \mathrm{C}\left(5,9 \times 10^{1} 0 \mathrm{UFC} / \mathrm{mL}\right)$ e esse comportamento ocorre devido esses microrganismos atingirem máximo de seu crescimento em temperaturas na faixa de 25 a $28^{\circ} \mathrm{C}$. A redução do $\mathrm{pH}$ e a contagem logarítmica total de aeróbio mesófilos são variáveis dependentes que apresentaram elevada correlação linear negativa (acima de 89\%) para as temperaturas estudadas. Esse resultado mostra o efeito da produção de ácidos orgânicos na fermentação natural de tucupi no pH. Conclusão: As temperaturas de fermentação de 30 e $40^{\circ} \mathrm{C}$ apresentaram resultados físico-químicos similares aos tucupis comerciais, quando comparadas a temperatura de 20 ${ }^{\circ} \mathrm{C}$, mas ainda serão necessários estudos de análise sensorial para correlacionar o nível de acidez produzido na fermentação com a aceitação de consumidores deste alimento.

Palavras-Chave: manihot, análise de alimentos, cinética, fungos

Agência de Fomento: CAPES - Coordenação de Aperfeiçoamento de Pessoal de Nível Superior; CNPq - Conselho Nacional de Desenvolvimento Científico e Tecnológico; FAPESPA - Fundação de Amparo à Pesquisa do Estado do Pará 